International Journal of Current Advanced Research

ISSN: O: 2319-6475, ISSN: P: 2319 - 6505, Impact Factor: SJIF: 5.995

Available Online at www.journalijcar.org

Volume 6; Issue 4; April 2017; Page No. 3562-3565

DOI: http://dx.doi.org/10.24327/ijcar.2017.3565.0315

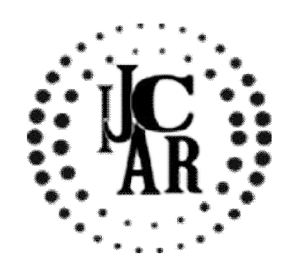

Research Article

\title{
HYPERPIGMENTED SKIN CONDITIONS: A STUDY OF PATTERN AND PREVALENCE FROM A TERTIARY CARE HOSPITAL OF NORTH INDIA
}

\author{
Mohammad Adil., Syed Suhail Amin., Tasleem Arif*., Konchok Dorjay., Dinesh Raj R \\ and Roopal Bansal
}

Department of Dermatology. Jawaharlal Nehru Medical College (JNMC), Aligarh Muslim University (AMU), Aligarh, India

\begin{tabular}{l}
\hline A R T I C L E I N F O \\
Article History: \\
Received $5^{\text {th }}$ January, 2017 \\
Received in revised form $25^{\text {th }}$ February, 2017 \\
Accepted $2^{\text {nd }}$ March, 2017 \\
Published online $28^{\text {th }}$ April, 2017 \\
\end{tabular}

Key words:

Hyperpigmentation, lichen planus pigmentosus, melasma, melanocytic nevi.

\begin{abstract}
A B S T R A C T
Background: Indians have a wide variety of skin color. Colored skin is more prone to a number of hyperpigmented skin conditions. This study was undertaken to study the prevalence and pattern of various hyperpigmented skin conditions in Western Uttar Pradesh, India.

Methods: A retrospective record based analysis of all patients presenting with complaints of skin hyperpigmentation during a period of one year from January to December 2016 was done. The diagnosis of all such conditions was noted and percentage calculated. The diseases were categorized into one of the etiological groups.

Results: Melasma was the commonest cause of hyperpigmentation seen in $2396(33.63 \%)$ patients followed by post inflammatory hyperpigmentation in $892(12.52 \%)$ patients, acquired melanocytic nevi in $533(7.48 \%)$ patients, lichen planus pigmentosus in 525 $(7.37 \%)$ patients and ephelids in $491(6.89 \%)$ patients. As an etiologic group, endocrinal cause was the commonest due to the inclusion of melasma in the group.

Conclusion: Melasma was the leading cause of hyperpigmentation. Post inflammatory hyperpigmentation and lichen planus pigmentosus are important causes of pigmentation in colored skin, unlike in fair skinned individuals.
\end{abstract}

Copyright $(2017$ Mohammad Adil et al. This is an open access article distributed under the Creative Commons Attribution License, which permits unrestricted use, distribution, and reproduction in any medium, provided the original work is properly cited.

\section{INTRODUCTION}

The skin in humans presents in a variety of shades depending on various factors like race, climate, light, ethnicity and race, anatomical site and lifestyle of the individual. Melanin and degree of melanization of the skin are the chief determinants of skin color. Melanin is produced by the melanocytes and is delivered to the keratinocytes in the form of small packets called melanosomes. One melanocyte delivers melanin to 36 keratinocytes and is referred to as epidermal melanin unit. ${ }^{1} \mathrm{~A}$ disease presenting with hyperpigmentation may be the result of one or more of the following factors: increase in epidermal melanin (ephelids, lentigines, tanning, nevus of Ota, Becker's nevus, etc), increase in dermal melanin (lichen planus, lupus erythematosus, post inflammatory pigmentation, incontinentia pigmenti), hemosiderin deposition (hemosiderosis), increased blood flow (hemangioma, superficial hemorrhage), thickened stratum corneum (pityriasis versicolor, acanthosis nigricans) blood in stratum corneum (black heel) or deposition of other pigments in the dermis (ochronosis, tattoo). ${ }^{2}$

\section{*Corresponding author: Tasleem Arif}

Department of Dermatology. Jawaharlal Nehru Medical College (JNMC),Aligarh Muslim University (AMU), Aligarh, India
The Indian skin is more prone to disorders of pigmentation than other human groups. ${ }^{3}$ This study aims to identify the common causes of pigmentation in North Indian patients and to determine the commonest category of diseases causing hyperpigmentation.

\section{METHODS}

This was a retrospective, hospital based descriptive study conducted in the department of dermatology, Jawaharlal Nehru Medical College from January 01, 2016 to December 31,2016 . The records of all patients attending the outpatient department during the study period were analyzed for patients presenting with complaints of hyperpigmentation and their diagnoses were noted. This were then categorized into one of the categories of disorders of hyperpigmentation. It is worth noting that only those patients who complained of hyperpigmentation were included in the study. Those having a disease of hyperpigmentation but not complaining about them were excluded from the study.

\section{RESULTS}

Of the 68,345 patients visiting the outpatient department, there were 7124 patients who presented with complaints of pigmentation. These constituted $10.42 \%$ of all patients 
visiting the department. The common causes of hyperpigmentation have been given in Table 1. An overwhelmingly large number of patients i.e. $2396(33.63 \%)$ had melasma.

Table 1 Common causes of hyperpigmentation

\begin{tabular}{cccc}
\hline S. No. & Disease & Number & Percentage \\
\hline 1. & Melasma & 2396 & $33.63 \%$ \\
2. & Post inflammatory & 892 & $12.52 \%$ \\
3. & hyperpigmentation & 533 & $7.48 \%$ \\
4. & Lichuired melanocytic nevi & 525 & $7.37 \%$ \\
5. & Ephelids & 491 & $6.89 \%$ \\
6. & Peri-orbital melanosis & 324 & $4.55 \%$ \\
7. & Seborrheic keratosis & 301 & $4.22 \%$ \\
8. & Acanthosis Nigricans & 253 & $3.55 \%$ \\
9. & Schamberg's disease & 246 & $3.45 \%$ \\
10. & Pityriasis versicolor & 238 & $3.34 \%$ \\
11. & Traumatic & 166 & $2.33 \%$ \\
12. & Fixed drug eruption & 107 & $1.50 \%$ \\
13. & Amyloidosis & 94 & $1.32 \%$ \\
14. & Exogenous ochronosis & 82 & $1.12 \%$ \\
15. & Eczema & 59 & $0.83 \%$ \\
\hline
\end{tabular}

There were 892 patients with post inflammatory hyperpigmentation, accounting for $12.52 \%$ patients. This was followed by acquired melanocytic nevi with $533(7.48 \%)$ patients and Lichen planus pigmentosus with 525 (7.37\%) patients. Ephelides constituted the fifth most common cause of hyperpigmentation affecting $491(6.89 \%)$ patients. 324 $(4.55 \%)$ patients presented with peri-orbital melanosis. Seborrheic keratosis affected $301(4.22 \%)$ patients followed by acanthosis nigricans in 253 (3.55\%), Schamberg's disease in $246(3.45 \%)$ and pityriasis versicolor in $238(3.34 \%)$ patients. On the categorization of hyperpigmentation on the basis of etiology, the group with the largest number of patients was endocrinal cause which was present in 2420 (33.97\%) patients. This was largely due to the inclusion of melasma in this category. The next most frequent cause was post inflammatory hyperpigmentation seen in 892 (12.52\%) patients. This was followed by the miscellaneous group with $674(9.46 \%)$ patients, which comprised of Scamberg's disease, peri-orbital melanosis, seborrheic melanosis and Erythromelanosis follicularis faciei et colli.

Table 2 Category-wise distribution of diseases causing hyperpigmentation

\begin{tabular}{|c|c|c|c|c|c|}
\hline S. No. & Category & Number & Percentage & Disease & Number \\
\hline \multirow[t]{2}{*}{1.} & Physiological & 47 & $0.66 \%$ & Pigmentary Demarcation lines & 8 \\
\hline & & & & Pregnancy related pigmentation & 39 \\
\hline \multirow[t]{8}{*}{2.} & Developmental & 642 & $9.01 \%$ & Becker's melanosis & 37 \\
\hline & & & & Nevus spillus & 2 \\
\hline & & & & Café au lait macules & 19 \\
\hline & & & & Lentiginosis & 28 \\
\hline & & & & Nevus of Ota & 8 \\
\hline & & & & Nevus of Ito & 5 \\
\hline & & & & Congenital melanocytic nevus & 10 \\
\hline & & & & Acquired melanocytic nevus & 533 \\
\hline \multirow[t]{5}{*}{3.} & Genetic & 498 & $6.99 \%$ & Ephelids & 491 \\
\hline & & & & Dowling Degos Disease & 2 \\
\hline & & & & Acropigmentation of Dohi & 1 \\
\hline & & & & Acropigmentation of Kitamura & 2 \\
\hline & & & & Dyschromatosis Universalis Hereditaria & 2 \\
\hline \multirow[t]{3}{*}{4.} & Physical & 183 & $2.57 \%$ & Radiodermatitis & 3 \\
\hline & & & & Traumatic & 166 \\
\hline & & & & Erythema ab igne & 14 \\
\hline 5. & Nutritional & 51 & $0.72 \%$ & Deficiencies of Vit B3, Vit B6, Vit C & 51 \\
\hline \multirow[t]{3}{*}{6.} & Metabolic & 348 & $4.88 \%$ & Amyloidosis & 94 \\
\hline & & & & Porphyrias & 1 \\
\hline & & & & Acanthosis Nigricans & 253 \\
\hline \multirow[t]{4}{*}{7.} & Endocrine & 2420 & $33.97 \%$ & Melasma & 2396 \\
\hline & & & & Cushing's syndrome & 5 \\
\hline & & & & Addison's disease & 1 \\
\hline & & & & Hyperthyroidism & 18 \\
\hline \multirow[t]{4}{*}{8.} & Drugs and chemicals & 127 & $1.78 \%$ & Phytophotodermatitis & 3 \\
\hline & & & & Fixed drug eruption & 107 \\
\hline & & & & Arsenic & 1 \\
\hline & & & & Antiretroviral therapy & 16 \\
\hline \multirow[t]{3}{*}{9 . } & Systemic diseases & 45 & $0.64 \%$ & Chronic liver disease & 9 \\
\hline & & & & Chronic renal disease & 14 \\
\hline & & & & Connective tissue diseases & 22 \\
\hline \multirow[t]{4}{*}{10.} & Inflammation & 653 & $9.17 \%$ & Lichen planus pigmentosus & 525 \\
\hline & & & & Erythema dyschromicum perstans & 57 \\
\hline & & & & Reihl's melanosis & 12 \\
\hline & & & & Eczema & 59 \\
\hline \multirow[t]{2}{*}{11.} & Infective & 239 & $3.35 \%$ & Tinea nigra & 1 \\
\hline & & & & Pityriasis versicolor & 238 \\
\hline \multirow[t]{3}{*}{12.} & Neoplastic & 305 & $4.28 \%$ & Basal cell carcinoma & 3 \\
\hline & & & & Mastocytosis & 1 \\
\hline & & & & Seborrheic keratosis & 301 \\
\hline 13. & Post inflammatory & 892 & $12.52 \%$ & & \\
\hline \multirow[t]{6}{*}{14.} & Miscellaneous & 674 & $9.46 \%$ & Seborrheic melanosis & 17 \\
\hline & & & & Erythromelanosis follicularis & 5 \\
\hline & & & & Periorbital melanosis & 324 \\
\hline & & & & Schamberg's disease & 246 \\
\hline & & & & Exogenous ochronosis & 82 \\
\hline & Total & 7124 & $100.0 \%$ & & \\
\hline
\end{tabular}


Inflammatory diseases were seen in 653 (9.17\%) people followed closely by developmental causes. These causes comprised mostly of various nevi and lentiginosis and were seen in $642(9.01 \%)$ patients. Genetic causes, which included ephelides, were seen in 498 (6.99\%) patients. Metabolic causes produced pigmentation in $348(4.88 \%)$ followed by neoplastic causes in $305(4.28 \%)$ patients. Infections caused pigmentation in $239(3.35 \%)$ while $183(2.57 \%)$ patients had pigmentation due to physical causes like heat and trauma. All causes of hyperpigmentation, on the basis of etiology have been tabulated in Table 2 .

\section{DISCUSSION}

Indian skin shows great variability in skin color and other specific features as India is home to a variety of ethnicities. ${ }^{4}$ A study from four cities of India demonstrated that facial skin color heterogeneity may be present in as high as $80 \%$ of people, regardless of age or sex. ${ }^{5}$ These factors have a profound effect on the quality of life and cause emotional distress to the sufferers. ${ }^{6}$ Disorders causing hyperpigmentation are more common in India than disorders causing hypopigmentation. ${ }^{7}$

We found that $10.42 \%$ of the total patients presented with one or the other complaints of hyperpigmentation. Melasma was the commonest disease, seen in a third of all patients. The prevalence of melasma has been estimated to be around 20$30 \%$, as was seen in other studies from India. ${ }^{5}$ Melasma is believed to be caused by a variety of factors. Family history is seen in half of the patients and hormonal factors play an important role. ${ }^{8}$ Sunlight is said to aggravate melasma in susceptible people. The presence of melasma in endocrinal cause of pigmentation was done for want of a better positioning of this disease entity in other groups. Melasma was the chief reason for the endocrinal cause being the topmost category of pigmentation.

Post inflammatory hyperpigmentation was the second commonest cause of hyperpigmented lesions seen in $12.52 \%$ patients. This is an acquired pigmentary disease produced due to end result of inflammation in diseases like acne, psoriasis, lichen planus, eczematous dermatitis and insect bites. Coloured skin is more likely to develop post inflammatory pigmentation, that too with greater severity. ${ }^{9,10}$ It may last for months and tends to be more severe in diseases with chronic, recurrent inflammations. ${ }^{11}$ Other studies also mention post inflammatory hyperpigmentation to be the second most common cause of dark skin lesions after melasma. ${ }^{12}$

Acquired melanocytic nevi (AMN) were seen in $7.48 \%$ patients in our study. AMN are defects in development of epidermal melanocytes. ${ }^{13}$ An average male has around 15 AMN on the body whereas females may have double the number. ${ }^{14}$ The incidence of melanoma is very low in India and so these AMN are not considered a cause of alarm. Most patients who presented with AMN did so for cosmetic reasons.

Lichen Planus Pigmentosus (LPP) patients formed $7.37 \%$ of the total. LPP is a variant of lichen planus characterized by slow onset of dark colored macules over sun exposed areas and flexures. LPP is fairly common in India and prevalence of $4.1 \%$ has been described in a previous study. ${ }^{15}$ The use of mustard and amla oil has been considered a risk factor for development of LPP. The considerably high percentage of patients with LPP in our study could be explained on the basis of almost universal practice of using the above oils on scalp in rural Western Uttar Pradesh, where a large number of our patients hail from.

Ephelides or freckles are small, poorly marginated pale brown macules that occur in fair individuals on sun exposed areas. An autosomal dominant mode of inheritance is proposed. The percentage of ephelids in a study from Kashmir, India showed a total of $3.5 \%$ of all patients attending the dermatology outpatient department. ${ }^{16}$ Our study showed a much lower number of patients with this disease entity due to colour differences in the patients of the two regions.

The percentage of patients with periocular melanosis in our study was $4.55 \%$. This is much less than the prevalence of periorbital melanosis reported by Sheth et al, which was $30 \%{ }^{17}$ This variability may be explained on the selection criteria of the patients. The above authors actively searched for the disease in the patients while we included only those presenting with the complaint of periocular pigmentation.

Seborrheic keratosis is a benign epidermal tumour usually seen in the middle aged and elderly that present as brown black papules with a stuck on appearance. Dermatosis papulosa nigra is a subtype that is common in dark skinned individuals on the face and neck. These were present in a $4.22 \%$ patients in our study.

Patients with acanthosis nigricans (AN) accounted for $3.55 \%$ of the patients. AN presents a symmetric, hyperpigmented, velvety plaque with a velvety texture seen usually over the neck and flexures.It is an indicator of insulin resistance in obese patients. $^{18}$

Schamberg's disease or progressive pigmented purpuric dermatosis is a form of capillaritis leading to extravasation of red cells and pigmentation of skin due to hemosiderin deposition. This disease was present in $3.45 \%$ of all patients in our study.

Pityriasis versicolor of hyperpigmented type was seen in $3.34 \%$ of patients with hyperpigmentation. Patients with colored skin are more likely to develop versicolor of pigmented type. This is produced due to increased melanosome size and altered distribution in epidermis. ${ }^{19}$

Hyperpigmentation of pressure points occurs due to repeated friction and trauma leading to hyperkeratosis as a protective response to the body. An example is hyperpigmentation of forehead in Muslims offering 'namaz'. $2.33 \%$ of the patients in our study had this cause of pigmentation. This might be due to the high number of Muslim patients that our hospital attracts.

Fixed drug eruption is the most common cutaneous adverse drug reaction seen in India. ${ }^{20}$ Our study too showed this entity to be the greatest contributor in the drugs and chemicals category. The commonest drugs causing this eruption are cotrimoxazole, non-steroidal anti-inflammatory drugs and metronidazole.

Amyloidosis was seen in $1.32 \%$ patients. Amyloidosis, particularly macular amyloidosis presents as a pigmented macule with a characteristic rippled pattern in the interscapular area.

Exogenous ochronosis is an acquired disorder characterized by deposition of ochre colored microscopic pigment in the 
dermis. It occurs commonly after use of hydroquinone containing topical formulations. ${ }^{21}$ The high prevalence of this disease points to the rampant and indiscriminate use of hydroquinone based combinations in the region, which is used by people to get fair skin.

Eczematous diseases like atopic dermatitis and lichen simplex chronicus are fairly common and can lead to hyperpigmentation, as seen in $0.83 \%$ of our patients.Several other causes of hyperpigmentation exist which were individually seen in less than $1 \%$ of our patients each.

\section{CONCLUSION}

Hyperpigmentation of the skin may be due to several reasons. Melasma is the major contributor to the load of patients with hyperpigmentation forming about a third of all patients. Post inflammatory hyperpigmentation is fairly common in colored skin and occupies the second spot. Other common causes of pigmentation include acquired melanocytic nevi, lichen planus pigmentosus and ephelides. As a group, endocrinal factors are the leading cause of hyperpigmentation, if melasma is included in it. This is followed by post inflammatory hyperpigmentation, miscellaneous conditions like periorbital pigmentation and Schamberg's disease, and by developmental causes that include various nevi.

\section{References}

1. Reddy KK, Lenzy YM, Brown KL, Gilchrest BA. Racial considerations: skin of color. In: Goldsmith LA, Katz SI, Gilchrest BA, Paller AS, Leffell DJ, Wolff K, editors. In: Fitzpatrick's dermatology in general medicine, 8th ed. New York: McGraw Hill; 2012. p.91-103.

2. Dhar S, Dutta P, Malakar R. Pigmentary disorders. In: Valia RG, Valia Ar, editors. IADVL testbook of dermatology, 3rd ed. Mumbai: Bhalani Publishers; 2008. p.736-797.

3. Jablonski NG, Chaplin G. The evolution of human skin coloration. J Hum Evol 2000;39:57-106.

4. Jaswal IJ. Pigmentary variation in Indian populations. Acta Anthropogenet 1983;7:75-83.

5. Hourblin V, Nouveau S, Roy N, de Lacharrière O. Skin complexion and pigmentary disorders in facial skin of 1204 women in 4 Indian cities. Indian J Dermatol Venereol Leprol. 2014;80:395-401.

6. Ortonne JP, Passeron T, Srinivas C. In: Pigmentary Disorders, Prevention, Treatment and Cosmetics Contributions. In: Srinivas C, Verschoore M, editors. Basic Science for Modern Cosmetic Dermatology. New Delhi: Jaypee Brothers Medical Publishers; 2015. p. 75-90.
7. Dogra S, Sarangal R. Pigmentary disorders: An insight, Pigment International. 2014;1:5-7.

8. Kang HY. Etiopathogenesis of melasma. In: Lahiri K, Chatterjee M, Sarkar R, editors. Pigmentary disorders. New Delhi: Jaypee brothers Medical publishers; 2014. p282-286.

9. Lacz NL, Vafaie J, Kihiczak NI, Schwartz RA. Postinflammatory hyperpigmentation: A common but troubling condition. Int J Dermatol. 2004;43:362-5.

10. Davis EC, Callender VD. Postinflammatory hyperpigmentation: A review of the epidemiology, clinical features, and treatment options in skin of color. $J$ Clin Aesthet Dermatol. 2010;3:20-31.

11. Ruiz-Maldonado R, Orozco-Covarrubias ML. Postinflammatory hypopigmentation and hyperpigmentation. Semin Cutan Med Surg 1997;16:36-43.

12. Nouveau S, Agrawal D, Kohli M, Bernerd F, Misra N, Nayak CS. Skin hyperpigmentation in Indian skin: Insights and best practices. Indian J Dermatol 2016; 61:487-495.

13. Mackie RM. Disorders of the cutaneous melanocyte. In: Burns $\mathrm{T}$, Breathnach SM, Cox N, Griffiths C, editors. Rook's Textbook of dermatology. 7th ed. Blackwell Science; 2004. p. 38.5-38.22.

14. Weedon D, Strutton G. Lentigenes, nevi and malignant melanoma. In: Weedon D, editor. Skin pathology. 2nd ed. Churchill Livingstone; 2002. p. 803-832.

15. Kanwar AJ, Dogra S, Handa S, et al. A study of 124 Indian patients with lichen planus pigmentosus. Clin Exp Dermatol 2003; 28:481-5.

16. Yaseen U, Hassan I. Prevalence of various skin disorders in school going children of Kashmir valley of North India: a cross sectional study. Indian J Paediatr Dermatol 2013; 14:67-72.

17. Sheth PB, Shah HA, Dave JN. Periorbital hyperpigmentation: A study of its prevalence, common causative factors and its association with personal habits and other disorders. Indian J Dermatol 2014; 59:151-157.

18. Sadeghian G, Ziaie H, Amini M, Ali NM. Evaluation of insulin resistance in obese women with and without acanthosis nigricans. $J$ Dermatol 2009; 36:209-12.

19. Aljabre SH, Alzayir AA, Abdulghani $\mathrm{M}$, et al. Pigmentary changes of tinea versicolor in dark skinned patients. Int J Dermatol 2001; 40:273-275.

20. Patel RM, Marfatia YS. Clinical study of cutaneous drug eruptions in 200 patients. Indian J Dermatol Venereol Leprol 2008; 74:430.

21. Zawar V, Mhaskar ST. Exogenous ochronosis following hydroquinone for melasma. $J$ Cosmet Dermatol 2004; 3:234-236.

\section{How to cite this article:}

Mohammad Adil et al (2017) ' Hyperpigmented Skin Conditions: A Study Of Pattern And Prevalence From A Tertiary Care Hospital Of North India', International Journal of Current Advanced Research, 06(04), pp. 3562-3565.

DOI: http://dx.doi.org/10.24327/ijcar.2017.3565.0315 